\title{
Life cycle optimization of energy-intensive processes using eco-costs
}

\author{
Etienne Bernier • François Maréchal • Réjean Samson
}

Received: 15 November 2011 / Accepted: 11 February 2013 / Published online: 4 April 2013

(C) Springer-Verlag Berlin Heidelberg 2013

\begin{abstract}
Purpose This study provides a general methodology to integrate LCA into a single- or multi-objective process design optimization context. It uses specific weightings for foreground emissions, for preventable background emissions and for unpreventable background emissions, for each impact category. It is illustrated for a natural gas combined cycle power plant with three scenarios to reduce its carbon dioxide emissions: $\mathrm{CO}_{2}$ capture and sequestration, fuel substitution with biogas or fuel substitution with synthetic gas from wood. Methods Assuming that the opportunity to prevent emissions elsewhere is an implicit part of the process design decision space, the optimal solution cannot waste such opportunities and is shown to minimize total life cycle costs, including emission avoidance costs based on the optimal combination of prevention and compensation measures in the background system. In the case study, background emissions are inventoried from the ecoinvent database, their compensation costs are derived from the Ecocosts 2007 impact assessment method and their prevention costs are estimated from the literature. The calculated avoidance costs (weightings) then show how the background system affects the final choice of $\mathrm{CO}_{2}$ reduction scenario.

Results and discussion In the case study, all three options partially shift environmental burdens to the background
\end{abstract}

Responsible editor: Hanna-Leena Pesonen

E. Bernier $(\bowtie) \cdot R$. Samson

Interuniversity Research Centre for the Life Cycle of Products,

Processes and Services (CIRAIG), Department of Chemical

Engineering, École Polytechnique de Montréal,

C.P. 6079 , succ. Centre-Ville,

Montréal, Québec H3C 3A7, Canada

e-mail: etienne.bernier@polymtl.ca

F. Maréchal

Industrial Energy Systems Laboratory, École Polytechnique

Fédérale de Lausanne, Station 9,

1015 Lausanne, Switzerland system, which can be prevented or compensated. The corresponding minimum avoidance cost is highest overall for the biogas option, thus putting it at a disadvantage. For a vast majority of ecoinvent processes, energy efficiency is important to minimize total avoidance costs because they are dominated by background $\mathrm{CO}_{2}$. Furthermore, prevention cost data gathering can be simplified in some cases, without distorting design decisions, using a $\mathrm{CO}_{2}$-only background inventory. The non- $\mathrm{CO}_{2}$ background inventory is more useful after process design, for procurement decisions.

Conclusions Over-investing in design modifications cannot achieve the same background impact reductions as a sensible green procurement policy. Thus, the proposed weighting methodology ensures that all types of design decisions integrate LCA without incorrectly assuming that emissions are necessarily unavoidable when in the background. Within a context of future emission taxes or tradable permits, the weightings can also anticipate the after-tax cost passed on by suppliers-a marketable benefit of LCA.

Recommendations Since many LCA studies are equivalent to design optimization problems, the proposed weighting methodology provides a single-score impact method relevant to decision-making as well as a straightforward approach to LCA interpretation in terms of detailing the optimal combination of applicable design modifications, prevention measures and compensation measures.

Keywords Avoidance cost $\cdot \mathrm{CO}_{2}$ capture $\cdot$ Eco-cost . Internalization - Optimization · Prevention cost $\cdot$ Weighting

\section{Introduction}

The design of an industrial process involves several decisions about variables such as equipment size, flow configuration and limits on operating temperatures and pressures. These decisions, which are often optimized using a simulation model and algorithms, affect the life cycle costs and the life cycle 
environmental impacts of the process. If environmental information is not fed properly to such models, the selected process configuration could fail to reduce impacts globally. Life cycle assessment (LCA) provides information on global impacts that a process designer would not otherwise be able to research exhaustively.

From a process designer's perspective, environmental information can be used several ways. Adopting a strategy that considers environmental protection as a design objective and not merely as a constraint on operations is useful to establish novel process configurations that achieve improved economic and environmental performances (Hugo and Pistikopoulos 2005), especially when economic and environmental performance criteria are optimized simultaneously from a life cycle perspective (Azapagic 1999). LCA becomes an effective evaluation tool to determine whether different process configurations iterated during optimization shift environmental impacts from one life cycle stage to another (raw materials extraction, transport, transformation, use, disposal etc.) or from one impact category to another (climate change, acidification, ecotoxicity, eutrophication, etc.).

However, LCA must be used carefully because it does not readily provide information on whether the individual emission sources which compose the life cycle impacts are easy or difficult to remove technologically. Such information is presumably needed because all else being equal, an optimal design would be expected to use larger quantities of inputs (such as fuel, acid, steel, etc.) with highly-preventable life cycle impacts and smaller quantities of inputs with poorly-preventable life cycle impacts. Also, LCA results by themselves cannot form an optimization objective function, one reason being that it would require a single-score impact method and there is no consensus on weighting emissions belonging to different impact categories. For example, when optimizing a power plant design, it would be impossible to choose between larger and smaller heat exchangers without first arbitrarily weighting the climate change impacts of the avoided fuel combustion and the ecotoxicological impacts of the additional metal mining. Similarly, smaller heat exchangers may be preferable if a lower-impact supply chain can be found for fuel but not for metal, and conversely, requiring information about the preventability of fuel and metal impacts. Fortunately, LCA can be combined advantageously with other tools to explore a process design space.

Multi-objective optimization (MOO) has been widely used with LCA in that context. LCA is typically performed first for the various material inputs to the process, and the optimization problem is then formulated as a function of decision variables in the process design space. In the formulation, the environmental performance is evaluated using economic and LCAbased indicators (Azapagic 1999). The optimization algorithm then produces a set of Pareto-optimal process configurations representing the best possible compromise between two or more indicators. However, when the number of LCA-based indicators is high (e.g. one for each mid-point impact category), the hyper-dimensional results become difficult to interpret. The number can be reduced without introducing arbitrary weightings using techniques that minimize the utopia point distance (Martinez and Eliceche 2009) or maximize the joint probability of meeting a series of emission targets (GuillenGosalbez and Grossmann 2010). Also, since most impact categories are correlated for energy-intensive processes (Azapagic and Clift 1999), some indicators may be considered redundant and may be removed, but exceptions would go unnoticed. However, even if a consensus on the indicators and methods existed, MOO would still only delay the need for weightings until after optimization and the question of arbitrariness would remain.

Comparatively, the eco-costs weighting methodology can merge LCA-based costs with other costs, leading to a single optimization objective that yields a unique optimal design solution. For each impact category, eco-costs are defined as the marginal prevention costs at the (regional or global) negligible risk level using the best available technology not entailing excessive costs (Vogtländer and Bijma 2000). Within a category, a substance-specific eco-cost is proportional to the characterization factor of a reputable impact method and is unrelated to the substance-specific prevention cost. In effect, eco-costs form a prevention-cost-weighted single-score method that is more appropriate for actiondriven, as opposed to awareness-driven, LCAs (Vogtländer and Bijma 2000). Eco-costs therefore potentially address the issue of weighting different impact categories in a process design optimization context. Indeed, the optimization can effectively be performed under a constraint of constant global impacts in each category (the negligible risk level), in which case there is no environmental damage dependent on design variables left to evaluate, thus removing the arbitrariness of such evaluation and increasing transparency.

None of the preceding methods assess prevention opportunities for the thousands of emission flows in the process life cycle specifically, even though these opportunities are implicitly part of the design space and may affect the optimal value of design variables. This assessment can be accomplished by expanding the process model to add design variables that simulate impact prevention decisions taken by the average suppliers represented in the LCA data. For example, our previous work (Bernier et al. 2008; Bernier et al. 2010; Bernier et al. 2012) evaluated the break-even $\mathrm{CO}_{2}$ tax required to make an optimized post-combustion $\mathrm{CO}_{2}$ capture process profitable in a natural gas combined cycle (NGCC) power plant. It showed that $\mathrm{CO}_{2}$ capture requires a higher $\mathrm{CO}_{2}$ tax rate to become profitable when impacts are considered with a life cycle perspective. In particular, $\mathrm{CO}_{2}$ and $\mathrm{CH}_{4}$ emitted by natural gas producers and $\mathrm{CO}_{2}$ transporters correspond to additional taxes that may well be passed down to the plant. 
But when the optimization model also considers the option to pay natural gas producers to reduce their own emissions, $\mathrm{CO}_{2}$ capture becomes profitable again at lower tax rates, which, in turn, could affect design decisions such as the preferred $\mathrm{CO}_{2}$ absorber height (Bernier et al. 2012). Presumably, further improvements are still possible by adding similar options throughout the life cycle recursively, a method that would be fastidious considering the number of elementary processes in a typical LCA database. A preferable method would ideally provide the equivalent information as part of an impact weighting method directly in LCA.

This article proposes an impact weighting method within LCA that is readily usable as part of the objective function in the context of a process design optimization that implicitly considers existing impact prevention opportunities throughout the process life cycle and elsewhere (compensation) as part of the design space, regardless of how these opportunities will be managed explicitly later in the project. This article shows that the proposed method is appropriate for many types of LCAbased decision-making, without requiring any subjective evaluation of environmental damage, and is fairly simple to implement for a wide variety of systems qualified as energyintensive. This is illustrated for the case of a NGCC plant with three $\mathrm{CO}_{2}$ emissions reduction options including $\mathrm{CO}_{2}$ capture and fuel substitution.

\subsection{Illustrative example}

Figure 1 illustrates the core concepts of this article for a simple example with: one design decision variable, the thickness of a fictitious insulating material (in fictitious units); one impact prevention opportunity within the life

a

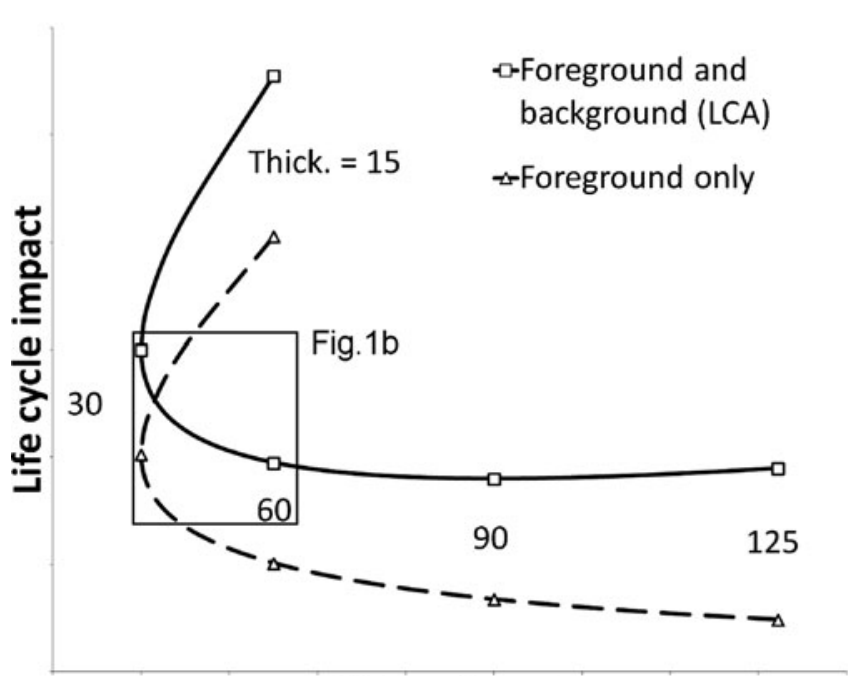

Life cycle cost cycle, a fictitious fuel production pathway with lower impacts but higher costs; and one impact prevention opportunity outside the life cycle, the purchase of a compensation credit at the eco-cost (cost at which such credits are guaranteed to exist). The choice of an optimal insulation thickness is assumed to be a simple compromise between the life cycle costs and impacts of the insulating material, proportional to thickness, and the life cycle costs and impacts of fuel to compensate for heat losses, inversely proportional to thickness.

In Fig. 1a, an important distinction is made between foreground impacts, which come from the fuel combustion products, and background impacts, which come from the rest of the fuel life cycle and from the insulating material life cycle. By definition, background impacts are considered remote from the design space, non-supplier-specific, typically modeled by life cycle inventory databases such as ecoinvent (Frischknecht et al. 2005) and therefore only preventable by suppliers themselves under various internal, government and customer incentives. The process designer should not be required to know impact prevention opportunities in the background exhaustively, as that would defeat the purpose of having a background system in LCA. In this case, the insulation thickness is to be optimized without knowing the optimal fuel production pathway explicitly.

In Fig. 1a, several thicknesses can be claimed to be optimal: 125 units (or infinity), which minimizes fuel usage and therefore the foreground impacts; 90 units, which minimizes the life cycle impacts according to traditional LCA; 30 units, which is the economic minimum neglecting environmental externalities; or anything in between, if various weightings are given to economic and environmental objectives. This

b

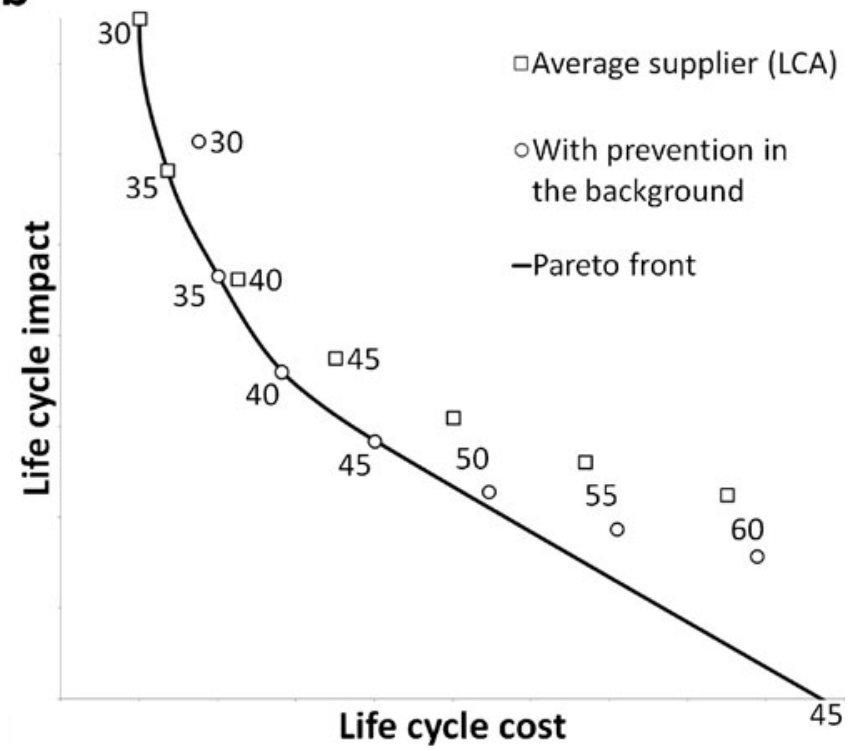

Fig. 1 Life cycle costs and impacts of a fictitious insulating material as a function of thickness 
ambiguity needs resolution because choosing a thickness may be required in an early design phase.

Figure $1 \mathrm{~b}$ shows more detail for thicknesses between 30 and 60 units, including both fuel production pathways (squares and circles) and the compensation credits (tangential straight line with eco-costs as slope). It shows that the goal of minimizing life cycle impacts for any given cost follows a precise path (Pareto front), starting from the economic optimum: first, increase thickness from 30 to 35 units; second, gradually blend in the low-impact fuel; third, increase thickness from 35 to 45 units; last, gradually purchase credits for the remaining impacts. Note that thicknesses between 45 and 90 units are suboptimal because they waste more compensation opportunities than they achieve in life cycle impacts reduction.

The thickness of 45 units plays a special role in this system: it is the only thickness compatible with the goal of achieving zero or negligible life cycle impacts at a minimum cost, or the goal of minimizing global impacts for a given cost (other than very low), independently of any subjective valuation of environmental damages. It only depends on the global risk levels setting the eco-costs, for which a sensitivity analysis can be performed. A thickness of 45 units is therefore a recommendable design decision from a life cycle thinking perspective, regardless of how prevention will be managed later.

Note that in Fig. 1b, the "average supplier" curve is tangential to the eco-cost slope for a thickness of 50 units. Therefore, neglecting the preventability of background impacts overestimates the optimal thickness in this case, an overinvestment leading to impacts from insulating material producers that are disproportionate with the impacts of the optimal fuel production pathway (unknown to the process designer).

The goal of the proposed weighting method is to provide an LCA-based objective function that will be minimized for a thickness of 45 units, in this case, by seamlessly anticipating the optimal fuel production pathway in the background.

\subsection{Theory}

Process design life cycle optimization, as proposed in this study, allows all impact prevention opportunities, throughout the life cycle of each input and elsewhere (compensation), as implicitly part of the design space. Simple calculus then indicates that global optimality requires that all emissions (foreground and background) be reduced up to the point at which the marginal prevention costs per unit of impact are globally uniform (Bernier et al. 2012). Fig. 2 illustrates the optimal combination of prevention and compensation to achieve

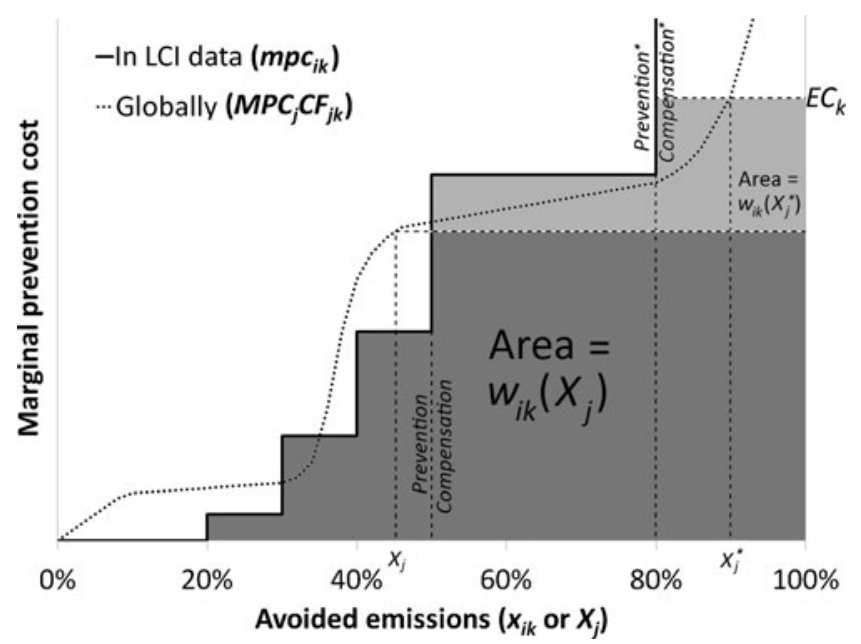

Fig. 2 Relationship between avoidance costs $\left(w_{i k}\right)$ and hypothetical prevention costs

zero life cycle emissions for a fictitious substance $k$ in the life cycle of input $i$. Table 1 describes the variables used.

In Fig. 2, $m p c_{i k}\left(x_{i k}\right)$ indicates the marginal cost per unit mass to prevent the fraction $x_{i k}$ of all emissions of substance $k$ throughout the background life cycle inventory (B-LCI) of input $i$. The discrete steps represent successive prevention technologies specific to input $i$; for example, particulate filters for diesel trucks throughout the supply chain. Comparatively, the dashed curve $M P C_{j}\left(X_{j}\right) \cdot C F_{j k}$ indicates the marginal cost per unit impact to prevent the fraction $X_{j}$ of all impacts in category $j$ globally, including for substances other than $k$, multiplied by the characterization factor of substance $k$ in category $j$. The soft steps represent widely applicable prevention technologies with small cost variations depending on local conditions; for example, particulate filters for all dust sources worldwide.

Assuming that the global impact reduction $X_{j}$ represents some expected policy outcome or some voluntary target that the optimal process design is required to be coherent with, then compensation becomes advantageous over prevention within the input $i$ B-LCI at the point where $m p c_{i k}\left(x_{i k}\right)$ reaches the height of $M P C_{j}\left(X_{j}\right) \cdot C F_{j k}$. For example, when the global impact reduction target is $45 \%\left(X_{j}=0.45\right)$ in Fig. 2, the optimal combination of measures for input $i$ is $50 \%$ prevention and $50 \%$ compensation at an average avoidance cost represented by the dark area $w_{i k}\left(X_{j}\right)$. When $X_{j}=0.9$ instead, the optimal combination is $80 \%$ prevention and $20 \%$ compensation at an average cost of $w_{i k}\left(X_{j}^{*}\right)$-an increase of about $22 \%$ indicated by the lighter area. Here, the asterisk denotes the strict target called negligible risk level at which, by definition, $M P C_{j} \cdot C F_{j k}$ becomes the 
Table 1 Variable definitions

\begin{tabular}{|c|c|c|c|}
\hline Variable name & Variable description & Unit & Comments \\
\hline$c_{i}$ & input cost & $€ /$ unit & Non-environmental cost of one unit of input $i$ \\
\hline$C\left(y_{d}\right)$ & overhead cost & $€$ & $\begin{array}{l}\text { Non-environment and non-input cost in the production of the final product for a } \\
\text { specific design scenario }\end{array}$ \\
\hline$C F_{j k}$ & characterisation factor & $\mathrm{kg}_{\text {eq }} / \mathrm{kg}$ & Impact of substance $k$ relative to a reference substance in impact category $j$ \\
\hline$E C_{k}$ & eco-cost & $€ / \mathrm{kg}$ & $\begin{array}{l}\text { Marginal prevention cost of substance } k \text { coherent with a globally (or regionally) } \\
\text { safe level of impacts (see } X_{j}^{*} \text { ) }\end{array}$ \\
\hline$F_{k}\left(y_{d}\right)$ & foreground emission & $\mathrm{kg}$ & $\begin{array}{l}\text { Quantity of substance } k \text { emitted in the production of the final product for a } \\
\text { specific scenario but unaccounted for by any } g_{i k} \text { (foreground as opposed to } \\
\text { background) }\end{array}$ \\
\hline$g_{i k}$ & life cycle inventory & $\mathrm{kg} /$ unit & $\begin{array}{l}\text { Quantity of emissions of substance } k \text { in the life cycle of one unit of input } i \\
\text { all } g_{i k} \text { together are referred to as the background life cycle inventory (B-LCI) }\end{array}$ \\
\hline$M_{i}\left(y_{d}\right)$ & reference flow & unit & Quantity of input $i$ in the final product for a specific scenario \\
\hline$m p c_{i k}\left(x_{i k}\right)$ & marginal prevention cost & $€ / \mathrm{kg}$ & $\begin{array}{l}\text { Cost to prevent emissions of substance } k \text { in the life cycle of input } i \text {, for the } x_{i k} \text { th } \\
\text { fraction starting with the most easily preventable }\end{array}$ \\
\hline$M P C_{j}\left(X_{j}\right)$ & marginal prevention cost & $€ / \mathrm{kg}_{\mathrm{eq}}$ & $\begin{array}{l}\text { Cost to prevent impacts in category } j \text { globally (or regionally), for the } X_{j} \text { th } \\
\text { fraction starting with the most easily preventable }\end{array}$ \\
\hline $\operatorname{obj}(\vec{X})$ & objective function & $€$ & $\begin{array}{l}\text { Minimum cost to produce the final product including the prevention or the } \\
\text { compensation of all life cycle impacts, when prevention efforts reach } \vec{X} \\
\text { globally (or regionally) }\end{array}$ \\
\hline$w_{i k}\left(X_{j}\right)$ & weighting factor / avoidance cost & $€ / \mathrm{kg}$ & $\begin{array}{l}\text { Minimum average cost to prevent or compensate all emissions of substance } k \text { in the } \\
\text { life cycle of input } i \text {, when prevention efforts reach } X_{j} \text { globally (or regionally) }\end{array}$ \\
\hline$w_{i}(\vec{X})$ & weighting factor / avoidance cost & $€ /$ unit & $\begin{array}{l}\text { Minimum average cost to prevent or compensate all emissions in the life cycle } \\
\text { of one unit of input } i \text {, when prevention efforts reach } \vec{X} \text { globally (or regionally) }\end{array}$ \\
\hline$W_{k}\left(y_{d}, \vec{X}\right)$ & weighting factor / avoidance cost & $€$ & $\begin{array}{l}\text { Minimum average cost to prevent or compensate all emissions of substance } k \text { in } \\
\text { the life cycle of the final product, excluding } F_{k} \text {, when prevention efforts reach } \\
\vec{X} \text { globally (or regionally) }\end{array}$ \\
\hline$x_{i k}$ & fraction of emissions & $\mathrm{kg} / \mathrm{kg}$ & $\begin{array}{l}\text { Fraction of emissions of substance } k \text { in the life cycle of input } i \text {; prevention is } \\
\text { more effective than compensation up to a point specific to each } i \text { and } k\end{array}$ \\
\hline$X_{j}$ & fraction of impacts & $\mathrm{kg}_{\mathrm{eq}} / \mathrm{kg}_{\mathrm{eq}}$ & $\begin{array}{l}\text { Fraction of impacts in category } j ; X_{j}^{*} \text { is the fraction to be prevented specifically } \\
\text { to reach a globally (or regionally) safe level }\end{array}$ \\
\hline$\vec{X}$ & fractions of impacts & N/A & Vector grouping $X_{j}$ for all impact categories; $\vec{X}^{*}$ groups $X_{j}^{*}$ for all impact categories \\
\hline$y_{d}$ & design decision variable & N/A & Variable to generate configuration scenarios for a process to optimize locally \\
\hline$y_{i k}$ & procurement decision variable & $\mathrm{N} / \mathrm{A}$ & $\begin{array}{l}\text { Variable to generate scenarios for the procurement of input } i \text { from suppliers } \\
\text { that emit less of substance } k\end{array}$ \\
\hline
\end{tabular}

eco-cost ( $E C_{k}$ in Fig. 2). In this case, $E C_{k}$ is determined by whatever prevention technology is applicable to the $91 \mathrm{st}$ global impact percentile in category $j$. Mathematically, $w_{i k}\left(<E C_{k}\right)$ is expressed by:

$$
w_{i k}(\vec{X})=\int_{0}^{1} \min \left\{m p c_{i k}\left(x_{i k}\right), \max _{j}\left[M P C_{j}(\vec{X}) \cdot C F_{j k}\right]\right\} d x_{i k}
$$

where $\vec{X}$ is the vector of each global impact reduction target $\left(X_{j}\right)$ for all categories, while the $\max _{j}$ function forbids double-counting between categories, as for ecocosts. Calculating $w_{i k}$ is straightforward as long as $m p c_{i k}$ can be approximated with a generic continuous function from literature without determining specific emissions prevention technologies for thousands of elementary processes in the B-LCI.
The $w_{i k}$ can be summed over $k$ to yield an input-specific avoidance cost $w_{i}$, or over $i$ to yield a scenario-specific avoidance cost $W_{k}$ for substance $k$ :

$w_{i}(\vec{X})=\sum_{k} g_{i k} \cdot w_{i k}(\vec{X})$

$W_{k}\left(\vec{y}_{d}, \vec{X}\right)=\sum_{i} M_{i}\left(\vec{y}_{d}\right) \cdot g_{i k} \cdot w_{i k}(\vec{X})$

where $g_{i k}$ is the substance $k$ final inventory for input $i$ in the B-LCI database, $M_{i}$ is the reference mass flow of input $i$ for a given process configuration, and $\vec{y}_{d}$ is a vector of discrete and continuous design decision variables (reactor size, choice of material, operating temperature, number of compression stages, etc.)

If $c_{i}$ is the cost of input $i$, then ranking inputs by $w_{i} / c_{i}$ is a good indicator of hotspots (environmental distortions in the 
price signal), and $c_{i}+w_{i}$ is a reasonable estimate of the future cost of input $i$ after complying with taxes or tradable emission permits when the global impact reductions go from zero to $\vec{X}$. Thus, if environmental damage is ever valued at more than $\operatorname{MPC}_{j}(\vec{X})$ for each category, it will always be possible and optimal to spend $w_{i}(\vec{X})$ or $W_{k}(\vec{X})$ to avoid the corresponding emissions. Consequently, these avoidance costs are useful as a weighting method in LCA because they provide the necessary information to immediately optimize the process configuration $\left(\vec{y}_{d}\right)$ under an implicit constraint of zero or minimal life cycle impacts. Only later phases in the project need to consider explicitly how suppliers will react under the future pressure of emission taxes, of tradable emission permits or of a green procurement policy to be determined later.

In a single-objective process design optimization context, the optimization objective function obj becomes the sum of all life cycle costs, including the average avoidance cost of all life cycle impacts. The negligible risk levels are then arguably the voluntary targets most coherent with a green design $\left(\vec{X}=\vec{X}^{*}\right)$. In that case, all emissions are valued at their eco-cost unless preventable at lower cost:

$o b j=\min _{\bar{y}_{d}}\left\{C\left(\vec{y}_{d}\right)+\sum_{k} F_{k}\left(\vec{y}_{d}\right) \cdot E C_{k}+\sum_{i}\left[c_{i}+w_{i}\left(\vec{X}^{*}\right)\right] \cdot M_{i}\left(\vec{y}_{d}\right)\right\}$

where $C$ represents non-input life cycle costs (wages, overhead etc.) and $F_{k}$ represents foreground emission flows. The $\vec{y}_{d}$ that minimizes obj then represents the optimal design in the same sense that 45 units is the optimal insulation thickness in Fig. 1.

The structure of Eq. 4 shows that an optimization algorithm will always react to an error in $w_{i}$ similarly to an error in $c_{i}$. However, in order to reach a better solution than when simply assuming $w_{i}$ proportional to $c_{i}$ - which requires no LCA - the error in $w_{i}$ cannot be allowed to exceed $100 \%$ (Bernier et al. 2012). Overestimating $w_{i}$ by more than $100 \%$ - a plausible outcome when the preventability of background emissions is poorly identified — can lead to an environmentally wasteful overutilization of all inputs other than $i$. Consequently, an underestimation bias is recommended for all $m p c_{i k}\left(x_{i k}\right)$.

In a multi-objective optimization (MOO) context, a few ( $n$, typically 1 ) environmental objectives are separated out of Eq. (4) and considered independently. In order to simultaneously optimize background and foreground emissions using MOO, procurement decision variables $\left(y_{i k}\right)$ are required to model marginal prevention cost functions $\left(m p c_{i k}\right)$. For example, the five $m p c_{i k}$ steps in Fig. 2 could be represented by five virtual suppliers for input $i$, in the same manner that the alternate fuel supply in Fig. $1 \mathrm{~b}$ represents a fixed impact reduction achieved at a fixed cost per unit fuel. The $n$ environmental objectives and the economic objective $\left(o b j_{n+1}\right)$ are then defined as:

$$
\begin{aligned}
& o b j_{1}=\sum_{k}\left[F_{k}\left(\vec{y}_{d}\right)+\sum_{i} M_{i}\left(\vec{y}_{d}\right) \cdot g_{i k}\left(y_{i k}\right)\right] C F_{1 k} \\
& o b j_{2}=\sum_{k}\left[F_{k}\left(\vec{y}_{d}\right)+\sum_{i} M_{i}\left(\vec{y}_{d}\right) \cdot g_{i k}\left(y_{i k}\right)\right] C F_{2 k} \\
& o b j_{n}=\sum_{k}\left[F_{k}\left(\vec{y}_{d}\right)+\sum_{i} M_{i}\left(\vec{y}_{d}\right) \cdot g_{i k}\left(y_{i k}\right)\right] C F_{n k} \\
& o b j_{n+1}=\left\{\begin{array}{c}
C\left(\vec{y}_{d}\right)+\sum_{k} F_{k}\left(\vec{y}_{d}\right) \cdot\left[E C_{k}\right]_{j>n} \\
+\sum_{i}\left[c_{i}\left(\vec{y}_{i k}\right)+\left[w_{i}\left(\vec{X}^{*}\right)\right]_{j>n}\right] \cdot M_{i}\left(\vec{y}_{d}\right)
\end{array}\right\}
\end{aligned}
$$

where each environmental objective is simply the LCA of the $\left(\vec{y}_{i k}, \vec{y}_{d}\right)$ configuration iteration, and the economic objective is similar to Eq. (4) but considers only the remaining impact categories $(j>n)$ to avoid double-counting. Note that the recommended underestimation bias implies the exclusion of all B-LCI emissions of unknown prevention cost.

Equation 5 with $n=1$ results in a two-dimensional Pareto front similar to Fig. 1b. That is particularly useful when one specific impact category is a large contributor in Eq. (4), its target $\left(X_{j}\right)$ is unknown, and the designer needs a good understanding of the interactions between design decisions and procurement decisions.

\section{Methods}

The basic method of this study is to provide upper-bound and lower-bound avoidance cost estimates $\left(w_{i k}\right)$ for the BLCI of a natural gas combined cycle (NGCC) power plant with $\mathrm{CO}_{2}$ capture and alternate fuel options and to investigate the relevance for decision-making. Four scenarios, described in Table 2, are considered. Their comparison is considered an adequate optimization problem with a simple and illustrative design space. In practice, a more detailed optimization such as fine-tuning the capture system configuration (absorber height, etc.) would involve a fundamentally similar comparison of thousands of computer-generated simulation scenarios.

\subsection{Case study description and problem formulation}

The base case is a NGCC power plant such as the General Electric STAG $107 \mathrm{H} / 109 \mathrm{H}$ with three options to reduce its flue gas $\mathrm{CO}_{2}$ emissions: $90 \%$ post-combustion $\mathrm{CO}_{2}$ capture, fuel substitution with synthetic natural gas (SNG) from wood and fuel substitution with a biogas mix. Power plant operation is assumed to be independent of fuel type. Operation with an optimized $\mathrm{CO}_{2}$ capture system reduces 
Table 2 Scenario descriptions

\begin{tabular}{lllll}
\hline Scenario name & Base case & $90 \%$ capture & SNG & Biogas \\
\hline Type of power plant & NGCC & NGCC & NGCC & NGCC \\
Type of $\mathrm{CH}_{4}$ fuel & FNG (fossil) & FNG (fossil) & SNG (from wood) & Biogas (purified) \\
Type of $\mathrm{CO}_{2}$ capture equipment & None & Post-combustion & None & None \\
Net output (MW electrical) & 400 & 363 & 400 & 400 \\
Flue gas (foreground) non- $\mathrm{CO}_{2}$ emissions model & $2400 \mathrm{GJ} / \mathrm{h} \mathrm{FNG}$ & $2400 \mathrm{GJ} / \mathrm{h} \mathrm{FNG}$ & $2400 \mathrm{GJ} / \mathrm{h} \mathrm{FNG}$ & $2400 \mathrm{GJ} / \mathrm{h} \mathrm{FNG}$ \\
Flue gas (foreground) fossil $\mathrm{CO}_{2}$ emissions & $134.4 \mathrm{t} / \mathrm{h}$ & $13.44 \mathrm{t} / \mathrm{h}$ & $0 \mathrm{t} / \mathrm{h}$ & $0 \mathrm{t} / \mathrm{h}$ \\
\hline
\end{tabular}

the electrical output while adding impacts related to $\mathrm{CO}_{2}$ transportation and sequestration (Bernier et al. 2010; Bernier et al. 2012). Fuel blends are not considered directly but can be interpolated from the results.

The post-combustion $\mathrm{CO}_{2}$ capture system uses reversible absorption with monoethanolamine (MEA). Its design was optimized in our previous study (Bernier et al. 2010), emphasizing thermal integration, using a state-of-the-art simulation platform with an evolutionary MOO algorithm (Bolliger et al. 2005). The resulting Pareto set, including the $90 \%$ capture configuration selected for this study, featured flue gas recirculation, a relatively wide absorber and steam generation below the MEA reboiler temperature. The $90 \%$ capture configuration had the lowest prevention cost for climate change, at $\$ 60.25 /$ ton $\mathrm{CO}_{2 \text { eq }}$ from a local perspective and $\$ 62.30$ /ton $\mathrm{CO}_{2 \mathrm{eq}}$ from a life cycle perspective (approximately $€ 0.045 / \mathrm{kg}$ $\mathrm{CO}_{2 \mathrm{eq}}$ ), based on costs of $\$ 7.80 / \mathrm{GJ}$ for natural gas and $\$ 20 /$ ton for $\mathrm{CO}_{2}$ transportation and sequestration (Bernier et al. 2010).

Table 3 summarizes the input flows $\left(M_{i}\right)$, equivalent to LCA reference flows, per MWh of net electricity output for all four scenarios in this study. Note that capture applies to all $\mathrm{CO}_{2}$ passing through capture equipment, captured or not, while transport only applies to captured $\mathrm{CO}_{2}$ passing through transport and sequestration. Additional $\mathrm{CO}_{2}$ capture in the supply chain (B-LCI) is considered in section 2.4.

\subsection{Life cycle emissions inventory model}

This study did not acquire new primary LCA data, since it investigates the role of background processes. The system boundary is thus implicitly identical to the boundary for the ecoinvent v2.0 process Natural gas, burned in combined cycle plant, best technology/RER. Only NGCC flue gas emissions are considered as a foreground process, with flows ( $F_{k}$ in Eqs. 4 and 5) for all scenarios assumed to be identical to the ecoinvent v2.0 process Natural gas, burned in combined cycle plant, best technology/RER except for fossil $\mathrm{CO}_{2}$, estimated at $56 \mathrm{~kg} / \mathrm{GJ}$ for the base case (as in ecoinvent), $5.6 \mathrm{~kg} / \mathrm{GJ}$ for the $90 \%$ capture scenario and $0 \mathrm{~kg} / \mathrm{GJ}$ for the biogenic fuels (last line in Table 2).

Background emissions for $1 \mathrm{MWh}$ (functional unit) of net electricity output (reference function) are compiled using the input mass flows $M_{i}$ (reference flows) in Table 3 and the B-LCI for each input $\left(g_{i k}\right)$ described as follows. For the three fuel production cycles, the B-LCI are the ecoinvent v2.0 processes Natural gas, high pressure, at consumer/RER for $i=F N G$ (fossil natural gas); Methane, 96 vol.-\%, from synthetic gas, wood, at plant/CH for $i=S N G$ (syntheric natural gas) and Methane, $96 \mathrm{vol}-\%$, from biogas, high pressure, at consumer/CH for $i=$ biogas. For the NGCC power plant infrastructure and chemicals $(i=$ $N G C C$ ), the B-LCI is based on a modified version of the ecoinvent v2.0 process Natural gas, burned in combined cycle plant, best technology/RER, in which the fuel production cycle and the flue gas (foreground) emissions have been removed to avoid double-counting.

The $\mathrm{CO}_{2}$ capture $\mathrm{B}-\mathrm{LCI}(i=$ capture and $i=$ transport $)$ are taken from a 2007 in-house study based on data provided by GDF SUEZ and on the ecoinvent v1.2 database. The $1000 \mathrm{MW}$ NGCC power plant model in that study differs from the $400 \mathrm{MW}$ one in this study. The functional unit was the production of $1 \mathrm{kWh}$ of electricity with or without $90 \%$

Table 3 Input flows per MWh of net electricity output (reference flows in background system)

\begin{tabular}{|c|c|c|c|c|c|}
\hline Input flow & Unit & Base case & $90 \%$ capture & SNG & Biogas \\
\hline NGCC power plant chemicals and infrastructure $\left(M_{N G C C}\right)$ & $\mathrm{GJ} / \mathrm{MWh}$ & 6.00 & 6.61 & 6.00 & 6.00 \\
\hline Fossil natural gas $\left(M_{F N G}\right)$ & $\mathrm{GJ} / \mathrm{MWh}$ & 6.00 & 6.61 & 0.00 & 0.00 \\
\hline Synthetic natural gas $\left(M_{S N G}\right)$ & $\mathrm{GJ} / \mathrm{MWh}$ & 0.00 & 0.00 & 6.00 & 0.00 \\
\hline Biogas mix $\left(M_{\text {biogas }}\right)$ & $\mathrm{GJ} / \mathrm{MWh}$ & 0.00 & 0.00 & 0.00 & 6.00 \\
\hline Capture chemicals and infrastructure $\left(M_{\text {capture }} @ 56\right.$ kg/GJ) & $\mathrm{kg} \mathrm{CO} / \mathrm{MWh}$ & 0 & 370 & 0 & 0 \\
\hline Transportation and sequestration $\left(M_{\text {transport }} @ 50.4\right.$ kg/GJ) & $\mathrm{kg} \mathrm{CO} / \mathrm{MWh}$ & 0 & 333 & 0 & 0 \\
\hline
\end{tabular}


$\mathrm{CO}_{2}$ capture using MEA. The original data, also used in our previous studies (Bernier et al. 2008; Bernier et al. 2010; Bernier et al. 2012), covered several B-LCI elements including fuel production, power plant construction and operation, absorbents, water, $\mathrm{CO}_{2}$ drying, recompression and sequestration, infrastructure, transportation, disposal, and more. Of the 33 elementary processes in the inventory, 14 are considered unrelated to $\mathrm{CO}_{2}$ capture, 7 are considered related to $i=$ capture (absorber steel, absorbent make-up, etc.) and 12 are considered related to $i=$ transport (pipeline construction, compressor energy, etc.) The equivalence with the present study is based on a unit of $\mathrm{CO}_{2}$, not electricity, to compensate for differences in power plant thermodynamic efficiencies.

\subsection{Impact assessment and eco-cost calculation methodologies}

This study uses the Ecocosts 2007 impact assessment method developed by Vogtländer and Bijma (2000) and Vogtländer et al. $(2001 ; 2002)$ and available at www.ecocostsvalue.com. Using the SimaPro 7.2.4 software, this method expresses LCA results directly in eco-cost $(€)$. The seven impact categories considered are:

- GWP for climate change: The characterization factors are based on 100-year horizon global warming potentials from the Intergovernmental Panel on Climate Change. The eco-cost is $€ 0.135 / \mathrm{kg} \mathrm{CO}_{2 \text { eq }}$, based on the marginal technology of offshore wind energy substitution. Note that eco-costs exceed the cost of $\mathrm{CO}_{2}$ capture technology for power plants, which occurs earlier in the global prevention cost curve $\left(M P C_{\mathrm{GWP}}\right)$.

- ACID for acidification: The characterization factors are from the University of Leiden CML-2 method. The ecocost is $€ 14.19 / \mathrm{kg} \mathrm{NH}$ eq, based on the marginal technology of zero emission stables. The eco-cost based on the reference substance in the method, $\mathrm{SO}_{2}$, is $€ 7.55 / \mathrm{kg}$ $\mathrm{SO}_{2 \text { eq. }}$.

- EUTRO for eutrophication: The characterization factors are from the University of Leiden CML-2 method, excluding atmospheric emissions of $\mathrm{NO}_{\mathrm{x}}$ and $\mathrm{NH}_{3}$ to avoid double-counting with ACID. The eco-cost is $€$ $3.60 / \mathrm{kg} \mathrm{PO}_{4 \mathrm{eq}}$, based on the marginal technology of sustainable manure processing.

- SMOG for photochemical oxidation: The characterization factors are from the University of Leiden CML-2 method. The eco-cost is $€ 8.90 / \mathrm{kg} \mathrm{C}_{2} \mathrm{H}_{4 \mathrm{eq}}$, based on the marginal technology of low-emissions gasoline engines and refineries.

- DUST for particulate emissions (winter smog): The characterization factors are from the University of Michigan IMPACT 2002+ method. The eco-cost is $€$ $27.44 / \mathrm{kgPM}_{2.5 \mathrm{eq}}$, based on the marginal technology of low-emissions diesel engines.
- ECOTOX for aquatic ecotoxicity: The characterization factors are from the University of Michigan IMPACT $2002+$ method. The eco-cost is $€ 802 / \mathrm{kg} \mathrm{Zn}$ eq, based on the marginal technology of galvanized steel substitution by corrosion-resistant coating systems. The eco-cost based on the reference substance in the method, triethylene glycol (TEG), is $€ 0.000572 / \mathrm{kg} \mathrm{TEG}_{\mathrm{eq}}$.

- CANCER for carcinogens (human health): The characterization factors are from the University of Michigan IMPACT $2002+$ method. The eco-cost is $€ 33.0 / \mathrm{kg}$ $\mathrm{PAH}_{\mathrm{eq}}$ based on the marginal technology of industrial hydrocarbon emissions mitigation. The eco-cost based on the reference substance in the method, chloroethylene, is $€ 0.00933 / \mathrm{kg} \mathrm{C}_{2} \mathrm{H}_{3} \mathrm{Cl}_{\text {eq }}$. Note that many prevention measures for DUST also remove carcinogens, helping to keep their eco-costs low.

Some of the preceding information was obtained by personal communication with Prof. Vogtländer. To avoid double-counting with GWP, there are no eco-costs for ozone depletion in the Ecocosts 2007 method. Also, this study does not consider resource eco-costs (water, land, energy, minerals, etc.) to avoid double-counting scarcity rents that may already be present in current resource prices (for example, the market value of mineral deposits that is in excess of discovery costs, or the market value of water that is in excess of pumping costs).

Note that debating the choice of marginal technologies in the Ecocosts 2007 method is beyond the scope of this study. The assumption is that these technologies, combined with all imaginable lower-cost technologies, are sufficient to bring emissions to a globally safe level. Stricter targets would increase eco-costs and increase the importance of prevention $\left(m p c_{i k}\right)$ over compensation $\left(M P C_{j}\right)$ for avoidance (Eq. (1)), but would not necessarily significantly increase the resulting avoidance costs $\left(w_{i k}\right)$. This is analogous to the situation in Fig. 2, where a $100 \%$ target difference $\left(X_{j}^{*}=\right.$ 0.90 vs. 0.45 ) only results in a $22 \%$ weighting difference because prevention costs for the next available segment are not far above the previous eco-costs. Since, in this case, the B-LCI consists mostly of manageable large-scale point sources, it is reasonable that only a small fraction of prevention costs would far exceed current eco-costs, limiting the influence of target controversies on weightings.

\subsection{Estimation of background emissions weightings}

This study considers separate upper and lower bounds for prevention costs $\left(m p c_{i k}\right)$ and global emission reduction targets $(\vec{X})$ because of their significant uncertainties. The $\vec{X}$ upper bound is given by the Ecocosts 2007 method, while the lower bound is zero except for GWP because a minimum GWP reduction target is required to make the $90 \%$ 
$\mathrm{CO}_{2}$ capture scenario profitable ( $€ 0.045 / \mathrm{kg} \mathrm{CO}_{2 \mathrm{eq}}$ ). Using Eq. (1), maximum and minimum avoidance costs $\left(w_{i k}\right)$ are then defined as:

$\max w_{i k}=\int_{0}^{1} \min \left\{m p c_{i k}^{\max }\left(x_{i k}\right), E C_{k}\right\} d x_{i k}$

$\min w_{i k}=\int_{0}^{1} \min \left\{m p c_{i k}^{\min }\left(x_{i k}\right), 0.045 C F_{\mathrm{GWPk}}\right\} d x_{i k}$

As indicated earlier, marginal prevention cost functions $\left(m p c_{i k}\right)$ are ideally approximated with a generic continuous function from literature (generic prevention costs specific to industry segments) instead of evaluating prevention technologies for thousands of emissions in the ecoinvent database. For example, Fig. 3 describes the $\mathrm{CH}_{4}$ prevention cost for North American natural gas producers in general ( $I=$ FNG, $k=\mathrm{CH}_{4}$ ) as estimated by the U.S. Environmental Protection Agency (1999). This data is a little outdated but its format is useful to illustrate the interpretation of $m p c_{i k}$. Each step corresponds to the successive implementation of technologies such as low-bleed pneumatics, green completions, compressor blow-down gas recovery, etc. The average prevention cost is $\$ 6.90 /$ ton $\mathrm{CO}_{2 \mathrm{eq}}(\min =\max =€ 0.13 / \mathrm{kg}$ $\mathrm{CH}_{4}$ ) for the first half and unknown (but higher) for the rest.

For the other large B-LCI contributors $\left(g_{i k} \cdot E C_{k}>\right.$ $€ 0.05 / \mathrm{GJ})$, the following observations are used to estimate prevention costs:

- (GWP) $\mathrm{CO}_{2}$ from mobile, diffuse or small sources: Applicable capture technology is considered prohibitive ( $m p c_{i k}>E C_{k}$ for the fraction of $g_{i k}$ from such sources).

- (GWP) $\mathrm{CO}_{2}$ from sequestration leaks: These emissions in the distant future represent questionable damage

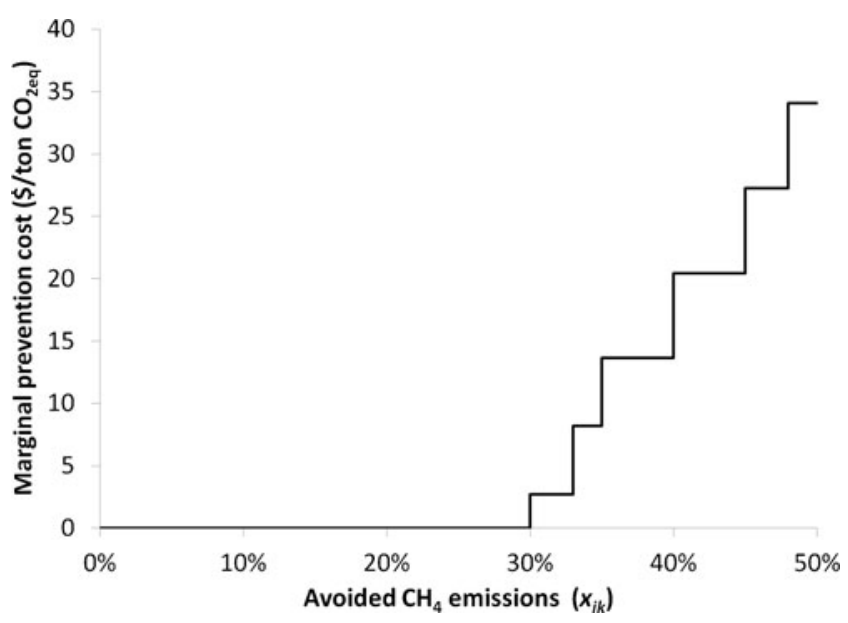

Fig. 3 Estimated prevention cost of $\mathrm{CH}_{4}$ emissions in the natural gas industry sector and/or their re-capture cost can be discounted $\left(m p c_{i k} \approx\right.$ 0 for the fraction of $g_{i k}$ emitted from long-term leaks).

- (GWP) $\mathrm{CO}_{2}$ from natural gas, synthetic gas and biogas purification: Purification provides highly concentrated $\mathrm{CO}_{2}$ ready for sequestration at a cost potentially as low as $€ 0.015 / \mathrm{kg}$ (Bernier et al. 2010; Simbolotti 2006) $\left(m p c_{i k}>€ 0.015 / \mathrm{kg}\right.$ for the fraction of $g_{i k}$ from natural gas purification). For example, if purification is done by membrane, the low-cost addition of a single stage allows for the simultaneous production of high-grade gas, high-grade $\mathrm{CO}_{2}$ and an intermediate stream for combustion on-site (Gassner et al. 2009). The upper bound is uncertain because the applicable fraction of $\mathrm{CO}_{2}$ in the ecoinvent data is also uncertain. The capture of biogenic $\mathrm{CO}_{2}$ is not considered at this point, but raises the possibility of negative prevention costs if sequestration is credited.

- (GWP) $\mathrm{CO}_{2}$ from other sources: Based on the postcombustion capture technology presently studied, as applied to other large scale sources of combustion gases, capture costs at least $€ 0.045 / \mathrm{kg}\left(m p c_{i k}>€ 0.045 / \mathrm{kg}\right.$ for the fraction of $g_{i k}$ from other sources). The upper bound is uncertain because capture becomes increasingly prohibitive for smaller sources.

- (GWP) $\mathrm{CH}_{4}$ from biogas purification: Significant resulting emissions can be avoided by low-cost flaring, by catalytic oxidation or by retrofitting the NGCC power plant to accept impure biogas directly $\left(m p c_{i k} \approx 0\right.$ for the fraction of $g_{i k}$ emitted during purification).

- (GWP) $\mathrm{CH}_{4}$ from natural gas producers: Fig. 3 already provides the first half of the prevention costs $(€ 0.13 / \mathrm{kg})$. For the other half, the prevention cost is at least $€ 0.63 / \mathrm{kg}$, which is the last step on Fig. 3, with no upper bound $\left(m p c_{i k}>€ 0.38 / \mathrm{kg}\right.$ on average for the fraction of $g_{i k}$ that is from natural gas producers).

- (Many) $\mathrm{CO}, \mathrm{C}_{2} \mathrm{H}_{4}$ and $\mathrm{CH}_{4}$ from charcoal production: These combustible gases can be avoided by inexpensive combustion in excess air $\left(m p c_{i k} \approx 0\right.$ for the fraction of $g_{i k}$ emitted during charcoal production).

- (ACID) $\mathrm{SO}_{\mathrm{x}}$ and $\mathrm{NO}_{\mathrm{x}}$ : The cost of flue gas desulfurization and selective catalytic reduction is low for large emitters that do not already use them. The upper bound is uncertain because the fraction of emissions in the ecoinvent data from such emitters is also uncertain. The lower bound is given by the reactant costs (lime and ammonia), about two orders of magnitude below eco-costs.

- (DUST) Particulates from wood gasifiers and diesel combustion (forestry equipment, off-shore $\mathrm{CO}_{2}$ compression stations, others): Prevention costs strongly depend on the exhaust gas initial particulate concentration, which is difficult to estimate from the ecoinvent data (no bounds). 
- (ECOTOX) Zn from canola cultivation: Such diffuse emissions of an essential nutrient from fertilizers and tire wear represent questionable damage in the distant future and may not need to be prevented at all $\left(m p c_{i k} \approx\right.$ 0 for the fraction of $g_{i k}$ emitted during cultivation).

- (Many) $\mathrm{N}_{2} \mathrm{O}, \mathrm{NH}_{3}, \mathrm{NO}_{3}$ and $\mathrm{PO}_{4}$ from canola cultivation: Data on the fertilizer management techniques specific to the ecoinvent dataset is insufficient to identify preventable or unpreventable emissions (no bounds).

Note that the preceding list is far from exhaustive and for illustrative purposes only. Also, SNG-related emissions will proportionally decrease as the technology matures and conversion efficiencies increase (Gassner et al. 2009; Gerber et al. 2009). Next generation gasification technologies could also substantially reduce $\mathrm{NO}_{\mathrm{x}}$ and particulate emissions, but these reductions are not easily translated into substancespecific prevention costs.

\subsection{Interpretation}

Assuming that the goal of the life cycle optimization is to achieve zero life cycle impacts at a minimum cost, or to minimize global impacts for a given cost (other than very low), the best scenario locally is the one that minimizes life cycle costs under a constraint of zero life cycle impacts (Eq. (4)) - as does the preferred thickness of 45 units in Fig. 1. In the present study, this choice can be done as soon as input costs are known, algorithmically or manually since there are only four scenarios. A sensitivity analysis could then be performed to determine if the choice of best scenario is affected when varying the avoidance costs between their upper and lower estimates (Eqs. (6) and (7)).

Rather than evaluating input costs, this article focuses on comparing the scenario-specific avoidance costs $\left(W_{k}\right)$, which are more directly related to LCA. In particular, if avoidance cost upper estimates (Eq. (6)) in can be shown to be negligible within Eq. 4 for some impact categories, then optimizing the corresponding impacts will necessarily affect procurement decisions but not process design decisions. The process design space can then be explored using multi-objective optimization, but simplicity would warrant not considering these categories as separate objectives.

\section{Results}

\subsection{LCA results}

Table 4 summarizes the LCA results using the Ecocosts 2007 method. In the top section, the results are given for the inputs in Table 3 in traditional LCA units per thermal GJ. In the middle section, the results are given for the four scenarios in traditional LCA units according to the reference function. In the bottom section, the same results are given as eco-costs in $€ / \mathrm{MWh}$ without any subsequent weighting based on prevention costs.

Table 4 shows that the $90 \% \mathrm{CO}_{2}$ capture scenario increases the non- $\mathrm{CO}_{2}$ impact by at least $10 \%$ relative to the base scenario. The difference is related to the decrease in power output and, to a lesser extent, to $\mathrm{CO}_{2}$ transportation. SNG has the lowest total impact in GWP, but the highest in many categories because of gasification by-products and the production of charcoal and rape methyl ester (from canola) for scrubbing.

When converting these impacts into eco-costs, the base case posts the highest eco-cost ( $€$ 58.20/MWh), the majority of which is due to flue gas $\mathrm{CO}_{2}$. The biogas scenario has the second highest eco-cost ( $€$ 32.89/MWh), the majority of which is due to methane emissions during biogas purification. However, these eco-costs do not reflect an optimal combination of prevention and compensation costs and cannot by themselves indicate which scenario can achieve the lowest emissions for a given cost, or which scenario can achieve zero life cycle impacts for the lowest cost.

\subsection{Avoidance costs (weightings)}

Table 5 lists all B-LCI pollutants with a significant contribution in Table $4\left(g_{i k} E C_{k}>€ 0.01 / \mathrm{GJ}\right)$, including their minimum and maximum avoidance costs (Eqs. (6), (7)) for each input. For each pollutant for each input, the largest data point (source localization within ecoinvent) and its percentage contribution (within $g_{i k}$ ) are also identified. Table 5 shows that each pollutant is rather unique in terms of single-source contribution, total contribution and ease of prevention. Consequently, the ratio between avoidance costs and eco-costs can be as low as $0 \%$ to $0.6 \%$ $\left(\mathrm{C}_{2} \mathrm{H}_{4}\right)$ and as high as $32 \%$ to $100 \%\left(\mathrm{CO}_{2}\right.$ excluding long-term).

Figure 4, which combines the results of Tables 4 and 5 , shows the total foreground and background eco-costs for each scenario. For each pollutant, the maximum avoidance cost $\left(\max W_{k}\right)$ is indicated by removing the avoidable fraction in Fig. 4. The minimum background avoidance cost (min $W_{k}$, not shown), as a fraction the maximum, is $32-33 \%$ for $\mathrm{CO}_{2}, 0-22 \%$ for $\mathrm{CH}_{4}$ and zero in the other impact categories because the minimum global impact reduction targets $\left(X_{j}\right)$ are also zero in this case (section 2.4). The real $W_{k}$ values are somewhere in between, depending on the actual prevention costs and global impact reduction targets, and other uncertainties. Note that the $\min W_{\mathrm{k}}$ for $\mathrm{CO}_{2}$ and $\mathrm{CH}_{4}$ combined is 
Table 4 LCA and eco-costs summary (italics = highest in category)

\begin{tabular}{|c|c|c|c|c|c|c|c|c|c|c|c|c|}
\hline \multirow{3}{*}{$\begin{array}{l}\text { Impact category } \\
\text { Unit (g or kg equivalents) } \\
\text { Substance }\end{array}$} & \multirow{2}{*}{\multicolumn{3}{|c|}{$\frac{\mathrm{GWP}}{\mathrm{kg} \mathrm{CO}}$}} & \multirow{2}{*}{\multicolumn{3}{|c|}{$\frac{\mathrm{ACID}}{\mathrm{g} \mathrm{SO}_{2}}$}} & \multirow{3}{*}{$\begin{array}{l}\text { EUTRO } \\
\mathrm{g} \mathrm{PO}_{4} \\
\text { All }\end{array}$} & \multirow{3}{*}{$\begin{array}{l}\text { SMOG } \\
\mathrm{g} \mathrm{C}_{2} \mathrm{H}_{4} \\
\text { All }\end{array}$} & \multirow{3}{*}{$\begin{array}{l}\text { DUST } \\
\mathrm{g} \mathrm{PM}_{2,5} \\
\text { All }\end{array}$} & \multirow{2}{*}{\multicolumn{2}{|c|}{$\frac{\text { ECOTOX }}{\text { kg TEG }}$}} & \multirow{3}{*}{$\begin{array}{l}\text { CANCER } \\
\mathrm{g} \mathrm{C}_{2} \mathrm{H}_{3} \mathrm{Cl} \\
\text { All }\end{array}$} \\
\hline & & & & & & & & & & & & \\
\hline & $\mathrm{CO}_{2}$ & $\mathrm{CH}_{4}$ & Other & $\mathrm{NO}_{x}$ & $\mathrm{SO}_{x}$ & Other & & & & Metal & Other & \\
\hline NGCC plant i\&c ${ }^{\mathrm{a}}$ (1 GJ) & 0.1 & 0.0 & 0.0 & 0.4 & 0.5 & 0.0 & 0.03 & 0.02 & 0.12 & 1.7 & 0.1 & 4.2 \\
\hline FNG production (1 GJ) & 7.5 & 3.9 & 0.0 & 16.2 & 22.5 & 1.5 & 0.29 & 1.35 & 0.69 & 17.8 & 0.6 & 578.5 \\
\hline SNG production (1 GJ) & 9.7 & 1.0 & 0.8 & 80.1 & 20.2 & 11.5 & 7.11 & 9.20 & 5.76 & 252.7 & 6.7 & 189.2 \\
\hline Biogas production (1 GJ) & 13.8 & 22.0 & 0.3 & 8.6 & 26.3 & 6.9 & 0.29 & 0.59 & 0.91 & 25.7 & 0.7 & 126.0 \\
\hline Capture i\&c ${ }^{\mathrm{a}}\left(56 \mathrm{~kg} \mathrm{CO}_{2}\right)$ & 0.5 & 0.0 & 0.0 & 2.0 & 0.8 & 0.0 & 0.03 & 0.10 & 0.33 & 2.0 & 0.2 & 1.7 \\
\hline Transport $^{\mathrm{b}}\left(50.4 \mathrm{~kg} \mathrm{CO}_{2}\right)$ & 2.5 & 0.0 & 0.0 & 0.2 & 0.2 & 0.1 & 0.04 & 0.01 & 0.03 & 2.7 & 0.0 & 2.5 \\
\hline Non- $\mathrm{CO}_{2}$ foreground (1 GJ) & 0.0 & 0.0 & 0.3 & 17.9 & 0.5 & 0.0 & 0.00 & 1.55 & 0.50 & 0.0 & 0.0 & 28.4 \\
\hline Scenario impact assessment: & & & & & & & & & & & & \\
\hline Base case (1 MWh) & 382 & 24 & 2 & 207 & 141 & 9 & 1.9 & 17.5 & 7.8 & 118 & 4 & 3,666 \\
\hline $90 \%$ capture $(1 \mathrm{MWh})$ & 107 & 26 & 2 & 242 & 163 & 11 & 2.6 & 20.0 & 11.0 & 161 & 7 & 4,067 \\
\hline SNG (1 MWh) & 59 & 6 & 7 & 590 & 127 & 69 & 42.8 & 64.6 & 38.3 & 1,527 & 41 & 1,330 \\
\hline Biogas (1 MWh) & 83 & 132 & 4 & 161 & 164 & 41 & 1.9 & 13.0 & 9.2 & 165 & 5 & 951 \\
\hline Scenario eco-cost assessment: & & & & & & & & & & & & \\
\hline Base case $(58.20 € / \mathrm{MWh})$ & 51.52 & 3.22 & 0.28 & 1.56 & 1.07 & 0.07 & 0.01 & 0.16 & 0.22 & 0.07 & 0.00 & 0.03 \\
\hline $90 \%$ capture $(22.09 € / \mathrm{MWh})$ & 14.45 & 3.56 & 0.32 & 1.83 & 1.23 & 0.08 & 0.01 & 0.18 & 0.30 & 0.09 & 0.00 & 0.04 \\
\hline SNG (18.29 €/MWh) & 7.94 & 0.81 & 0.91 & 4.45 & 0.96 & 0.52 & 0.15 & 0.58 & 1.05 & 0.87 & 0.02 & 0.01 \\
\hline Biogas (32.89€/MWh) & 11.25 & 17.88 & 0.52 & 1.22 & 1.24 & 0.31 & 0.01 & 0.12 & 0.25 & 0.09 & 0.00 & 0.01 \\
\hline
\end{tabular}

${ }^{\mathrm{a}}$ Infrastructure and chemicals

${ }^{\mathrm{b}} \mathrm{CO}_{2}$ drying, pipelining and sequestration in a saline aquifer, including on-shore and off-shore infrastructure

higher than the $\max W_{k}$ for all other substances combined, except for the SNG scenario. Avoiding background $\mathrm{CO}_{2}$ and $\mathrm{CH}_{4}$ is therefore costlier, and more important to the final choice of scenario, than avoiding all other substances, even if the global prevention efforts end up the least severe for climate change and the most severe for all other impact categories.

Under most circumstances, scenario ranking by total background avoidance costs is identical to the ranking by background $\mathrm{CO}_{2}$ only, which is predominant. Therefore, the LCA background component is least favourable to the biogas option within a wide range of prevention cost and global impact reduction target uncertainties. It is most favourable to the SNG option, which benefits from relatively low compensation costs for its high EUTRO, SMOG, DUST and ECOTOX impacts, and from a good improvement potential (conversion efficiencies, $\mathrm{NO}_{x}$ emissions, biogenic $\mathrm{CO}_{2}$ sequestration).

Of course, the final choice of scenario should be based on an appropriate objective function (Eq. (4)). This is beyond the scope of this study because it requires the life cycle costing of each scenario and a detailed analysis of $\mathrm{CO}_{2}$ capture and sequestration economics, including $\mathrm{CO}_{2}$ from the purification of all three fuels.

\subsection{Generalization to other energy-intensive processes}

Figure 5 shows the distribution of eco-costs (without any subsequent weighting) for 3,850 ecoinvent v2.0 processes with positive total eco-costs. In total, $70 \%$ have over $50 \%$ of their eco-costs in $\mathrm{CO}_{2}$ alone, while less than $11 \%$ have over $50 \%$ of their eco-costs in another category, including many processes related to agriculture, mining and waste disposal. Therefore, a vast majority of ecoinvent processes can be qualified as energy-intensive in the sense that they reproduce the patterns observed in the case study: most eco-costs result from hydrocarbon combustion products, of which $\mathrm{CO}_{2}$ is the largest contributor despite a relatively low eco-cost per unit mass.

Furthermore, when avoidance costs are considered, $\mathrm{CO}_{2}$ takes on even more relative importance for most of the 3,850 processes. Indeed, $\mathrm{CO}_{2}$ can only be prevented in significant amounts by capture from a small number of stationary sources. Comparatively, as discussed in section 2.4, prevention costs are well below eco-costs for concentrated sources of combustion products (particulates, $\mathrm{SO}_{x}$ and $\mathrm{NO}_{x}$ ) and other gases $\left(\mathrm{CH}_{4}, \mathrm{HFCs}\right)$ representing a significant fraction of non$\mathrm{CO}_{2}$ GWP, ACID and DUST, while the need to prevent ecotoxicity is questionable for some metals because of longterm bioaccessibility considerations. Consequently, energyrelated $\mathrm{CO}_{2}$ will represent the majority of background 
Table 5 Avoidance costs for major pollutants (Italics when maximum is lower than eco-cost)

\begin{tabular}{|c|c|c|c|c|c|c|c|c|}
\hline $\begin{array}{l}\text { Input } \\
\mathrm{i}\end{array}$ & $\begin{array}{l}\text { Category } \\
\text { j }\end{array}$ & $\begin{array}{l}\text { Pollutant } \\
\mathrm{k}\end{array}$ & $\begin{array}{l}g_{i k} \cdot E C_{k} \\
€ / G \mathrm{~J}\end{array}$ & $\begin{array}{l}\text { Largest source } \\
\text { localization }\end{array}$ & $\begin{array}{l}\text { Contribution } \\
\% g_{i k}\end{array}$ & $\begin{array}{l}E C_{k} \\
€ / \mathrm{kg}\end{array}$ & $\begin{array}{l}\max w_{i k} \\
€ / \mathrm{kg}\end{array}$ & $\begin{array}{l}\min _{€ / \mathrm{kg}} w_{i k} \\
\end{array}$ \\
\hline \multirow[t]{8}{*}{ Natural gas production } & GWP & $\mathrm{CO}_{2}$ & 1.01 & Compressor stations & $39 \%$ & 0.135 & 0.135 & 0.043 \\
\hline & GWP & $\mathrm{CH}_{4}$ & 0.53 & Pipelines & $59 \%$ & 3.38 & 1.76 & 0.38 \\
\hline & ACID & $\mathrm{SO}_{2}$ & 0.17 & Sour gas turbine & $77 \%$ & 7.55 & 7.55 & 0.00 \\
\hline & ACID & $\mathrm{NO}_{\mathrm{x}}$ & 0.12 & Compressor stations & $45 \%$ & 5.29 & 5.29 & 0.00 \\
\hline & DUST & Particulate & 0.02 & Diesel combustion (many) & $61 \%$ & 27.44 & 27.44 & 0.00 \\
\hline & ACID & $\mathrm{H}_{2} \mathrm{~S}$ & 0.01 & Upstream production & $99 \%$ & 14.19 & 14.19 & 0.00 \\
\hline & SMOG & $\mathrm{C}_{2} \mathrm{H}_{6}$ & 0.01 & Upstream production & $46 \%$ & 1.09 & 1.09 & 0.00 \\
\hline & CANCER & PAH & 0.01 & Upstream production & $97 \%$ & 33.00 & 33.00 & 0.00 \\
\hline \multirow[t]{4}{*}{$\mathrm{CO}_{2}$ transport sequestration } & GWP & $\mathrm{CO}_{2}$ & 0.40 & Sequestration leak & $80 \%$ & 0.135 & 0.023 & 0.008 \\
\hline & ACID & $\mathrm{NO}_{\mathrm{x}}$ & 0.02 & Off-shore compressor & $60 \%$ & 5.29 & 5.29 & 0.00 \\
\hline & DUST & Particulate & 0.01 & Diesel combustion (many) & $80 \%$ & 27.44 & 27.44 & 0.00 \\
\hline & ACID & $\mathrm{SO}_{2}$ & 0.01 & Coal power plants & $33 \%$ & 7.55 & 7.55 & 0.00 \\
\hline \multirow[t]{14}{*}{ SNG production from wood } & GWP & $\mathrm{CO}_{2}$ & 1.31 & Diesel combustion (many) & $35 \%$ & 0.135 & 0.135 & 0.045 \\
\hline & ACID & $\mathrm{NO}_{\mathrm{x}}$ & 0.60 & Gasification & $53 \%$ & 5.29 & 5.29 & 0.00 \\
\hline & DUST & Particulate & 0.16 & Diesel combustion (many) & $42 \%$ & 27.44 & 27.44 & 0.00 \\
\hline & ACID & $\mathrm{SO}_{2}$ & 0.15 & Sulfuric acid production & $20 \%$ & 7.55 & 7.55 & 0.00 \\
\hline & GWP & $\mathrm{CH}_{4}$ & 0.13 & Charcoal production & $60 \%$ & 3.38 & 1.35 & 0.00 \\
\hline & ECOTOX & $\mathrm{Zn}$ & 0.12 & Canola cultivation & $46 \%$ & 802 & 434 & 0.00 \\
\hline & GWP & $\mathrm{N}_{2} \mathrm{O}$ & 0.10 & Canola cultivation & $64 \%$ & 40.23 & 40.23 & 0.00 \\
\hline & ACID & $\mathrm{NH}_{3}$ & 0.07 & Canola cultivation & $88 \%$ & 14.19 & 14.19 & 0.00 \\
\hline & SMOG & $\mathrm{CO}$ & 0.06 & Charcoal production & $44 \%$ & 0.24 & 0.14 & 0.00 \\
\hline & EUTRO & $\mathrm{NO}_{3}^{-}$ & 0.02 & Canola cultivation & $93 \%$ & 0.36 & 0.36 & 0.00 \\
\hline & ACID & $\mathrm{H}_{2} \mathrm{~S}$ & 0.02 & Sanitary landfill & $74 \%$ & 14.19 & 14.19 & 0.00 \\
\hline & EUTRO & $\mathrm{PO}_{4}^{-}$ & 0.01 & Canola cultivation & $23 \%$ & 3.60 & 3.60 & 0.00 \\
\hline & SMOG & $\mathrm{C}_{2} \mathrm{H}_{4}$ & 0.01 & Charcoal production & $99 \%$ & 8.90 & 0.05 & 0.00 \\
\hline & GWP-ozone & CFC-14 & 0.01 & Aluminum for trailers & $100 \%$ & 998 & 998 & 0.00 \\
\hline \multirow[t]{9}{*}{ Biogas mix production } & GWP & $\mathrm{CH}_{4}$ & 2.98 & Biogas purification & $73 \%$ & 3.38 & 0.90 & 0.00 \\
\hline & GWP & $\mathrm{CO}_{2}$ & 1.86 & Boiler & $66 \%$ & 0.135 & 0.135 & 0.045 \\
\hline & ACID & $\mathrm{SO}_{2}$ & 0.20 & Biogas purification & $61 \%$ & 7.55 & 7.55 & 0.00 \\
\hline & ACID & $\mathrm{NO}_{\mathrm{x}}$ & 0.06 & Boiler & $17 \%$ & 5.29 & 5.29 & 0.00 \\
\hline & GWP & $\mathrm{N}_{2} \mathrm{O}$ & 0.04 & Waste digest/compost & $67 \%$ & 40.23 & 40.23 & 0.00 \\
\hline & ACID & $\mathrm{H}_{2} \mathrm{~S}$ & 0.03 & Waste digest/compost & $88 \%$ & 14.19 & 14.19 & 0.00 \\
\hline & DUST & Particulate & 0.02 & Diesel combustion (many) & $20 \%$ & 27.44 & 27.44 & 0.00 \\
\hline & ACID & $\mathrm{NH}_{3}$ & 0.02 & Waste digest/compost & $93 \%$ & 14.19 & 14.19 & 0.00 \\
\hline & ECOTOX & $\mathrm{Cr}$ & 0.01 & Electricity distribution & $54 \%$ & 259 & 259 & 0.00 \\
\hline NGCC infra/chem & GWP & $\mathrm{CO}_{2}$ & 0.02 & Diesel combustion (many) & $38 \%$ & 0.135 & 0.135 & 0.045 \\
\hline
\end{tabular}

avoidance costs for many process designs in various industries even if they do not directly belong to the energy sector.

\section{Discussion}

In a process design optimization context, Figs. 4 and 5 convincingly illustrate why the non- $\mathrm{CO}_{2} \mathrm{~B}-\mathrm{LCI}$ is inconsequential to configuration decisions (as opposed to procurement decisions) when all inputs are energy-intensive (as defined just above), regardless of the concern for a specific impact category. The cost to prevent or compensate background non- $\mathrm{CO}_{2}$ emissions is too low to contribute significant terms to Eq. (4) that could affect configuration decisions locally. For example, in Fig. 1b, the optimal thickness can vary between 45 and 50 units because the two fuel supply options cost differently (typical of $\mathrm{CO}_{2}$ ). If background impacts were instead avoidable at a low cost (typical of non- $\mathrm{CO}_{2}$ ), then a near-zero-impact supplier would be selected for each input and the optimal thickness 


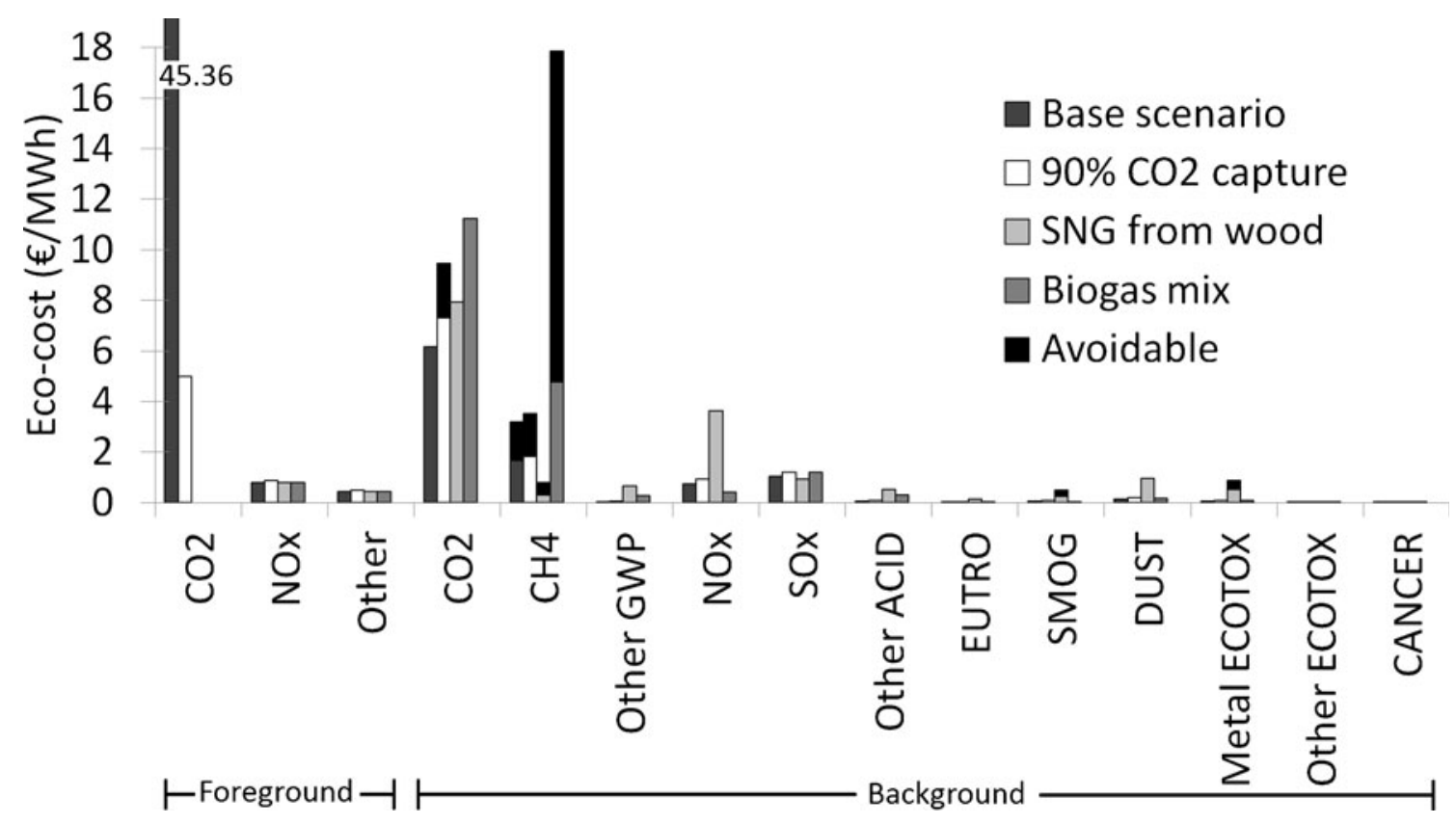

Fig. 4 LCA results for four NGCC power plant scenarios expressed as eco-costs

would be found simply by drawing the eco-cost line tangentially to the foreground impact curve on Fig. 1a.

Consequently, as long as all inputs can be qualified as energy-intensive, the B-LCI component of the objective function(s) is expected to favour process configurations moderately biased towards energy efficiency in order to decrease $W_{k}$ for $\mathrm{CO}_{2}$. For future design optimization studies, the use of a $\mathrm{CO}_{2}$-only $\mathrm{B}$-LCI-except for inputs that are not energy-intensive - would simplify avoidance cost estimates while being less distortive than a full B-LCI incorrectly assumed to only contain unavoidable emissions (overestimating $w_{i}$ as discussed in section 1.2).
Since $\mathrm{CO}_{2}$ belongs to $j=\mathrm{GWP}$, internal process configuration decisions relating to $\mathrm{CO}_{2}$ capture or $\mathrm{SNG}$ gasification can be determined by a multi-objective optimization focused on life cycle costs and life cycle GWP, as done previously (Bernier et al. 2010; Bernier et al. 2012; Gerber et al. 2009). For these specific decisions and except for those directly affecting foreground non- $\mathrm{CO}_{2}$ emissions, the consideration of additional impact categories would not have sufficient effect to warrant re-optimization, no matter the subjective concern assigned to each category. The impact in these categories can be efficiently reduced through procurement decisions only.

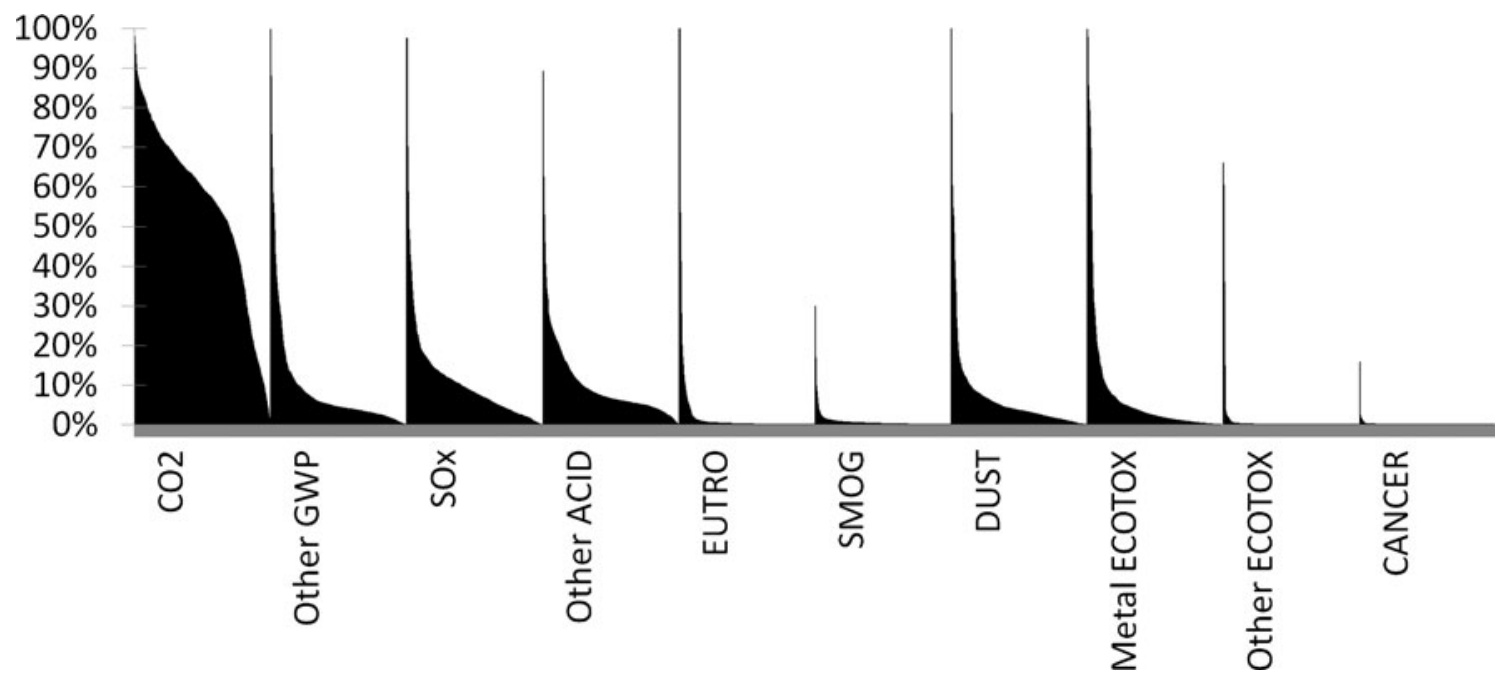

Fig. 5 Distribution of eco-costs over 3850 ecoinvent v2.0 processes 
For energy-intensive inputs, each $w_{i}$ simply anticipates how future $\mathrm{CO}_{2}$ compensation costs or taxes will affect each supplier. Looking back at Eq. (4) for any process in general, it follows that the set of local design decisions $\left(\vec{y}_{d}\right)$ most coherent with the goal of minimizing life cycle impacts is in fact nearly identical to the purely economic optimum (on the basis of life cycle costing) as long as prevention and compensation costs are included for life cycle $\mathrm{CO}_{2}$, for foreground non- $\mathrm{CO}_{2}$ and for a select few non- $\mathrm{CO}_{2}$ hot-spots in the background life cycle inventory. Any other process configuration, even if favourable from a traditional LCA perspective (such as the thickness of 90 in Fig. 1), will waste more compensation opportunities than it will achieve in reducing life cycle impacts.

\section{Conclusions}

This study provides a theoretical framework for weighting the secondary data (background processes) in LCA databases such as ecoinvent in a process design optimization context (single-objective or multi-objective). Inadequate methodologies may over-emphasize expensive process modifications or input substitutions while wasting the opportunity to prevent, neutralize, compensate or otherwise mitigate more environmental impacts in the background or elsewhere. Instead, we propose a life cycle optimization methodology that minimizes the cost to achieve zero life cycle impacts (or minimizes life cycle impacts for a given budget, which is equivalent in terms of process design decisions locally). In that context, the appropriate weighting of emissions is the minimum average cost to either prevent or compensate them (avoidance cost) in relation with a global impact reduction target. Bridging LCA and life cycle cost analysis, it is a valid methodology for any type of green design decision-making for which the opportunity to avoid more impacts elsewhere is implicitly considered to be a part of the decision space.

An NGCC power plant with three $\mathrm{CO}_{2}$ reduction options (fuel substitution by synthetic natural gas or biogas and post-combustion $\mathrm{CO}_{2}$ capture and sequestration) was chosen for the case study. While the final choice will depend on many considerations, we have shown that biogas is at a disadvantage because of its higher background $\mathrm{CO}_{2}$ and $\mathrm{CH}_{4}$ avoidance costs. Comparatively, synthetic gas is at an advantage because of its lower background avoidance costs despite having the worst environmental performance in most categories. Consequently, the subjective concern for each impact category is not the primary determinant for this decision or, more generally, for process design decisions unrelated to foreground emissions. For example, concern for SMOG would justify the procurement decision of avoiding SNG scrubbed using charcoal from producers that use outdated technology, but would not justify the design decision of avoiding SNG altogether, or even the decision of replacing charcoal as a scrubbing agent.

In many different systems, most inputs are energyintensive because their own background avoidance costs are dominated by hydrocarbon combustion products and primarily $\mathrm{CO}_{2}$. For the life cycle optimization of any design relying exclusively on such inputs, we have shown that a $\mathrm{CO}_{2}$-only background life cycle inventory (B-LCI) is satisfactory and simplifies prevention cost data gathering. $\mathrm{CO}_{2}$ B-LCI data reflect the potential future $\mathrm{CO}_{2}$ taxes passed on by suppliers, making LCA also attractive to industries that are not chiefly interested in environmental performance. Comparatively, non- $\mathrm{CO}_{2}$ BLCI data are more relevant in other contexts, including when working to determine an optimal combination of voluntary incentives for suppliers to reduce their own non- $\mathrm{CO}_{2}$ emissions as part of a green procurement strategy.

\subsection{Recommendations}

To facilitate optimization or design more generally, prevention cost data could play a role in future LCA databases by, for example, constituting an optional data field. The capacity to generate scenarios in which impacts are prevented up to a specified cost would be useful in many contexts, including macro-level simulations of future impacts.

Seeing that many LCA studies are effectively aimed at design optimization problems, the weightings presented in this study $\left(w_{i k}\right)$ can be considered appropriate for a singlescore impact method, enabling the following straightforward LCA interpretation procedure detailing the environmentally optimal combination of design modifications, prevention measures and compensation measures for the final user:

- LCA is performed for each design option or scenario using the eco-costs impact method. The results are split in (1) $\mathrm{CO}_{2}$, (2) foreground non- $\mathrm{CO}_{2}$, (3) major background non- $\mathrm{CO}_{2}$ (significant $g_{i k} \cdot E C_{k}$ compared to $\mathrm{CO}_{2}$ ), and (4) minor background non- $\mathrm{CO}_{2}$.

- In keeping with the previously recommended underestimation bias, prevention costs $\left(m p c_{i k}\right)$ are modelled for (2) and (3), while (1) is assumed unavoidable and (4) is assumed avoidable at no cost, for simplicity. Then, (2) and (3) are split between avoidable (2a and $3 a$ ) and unavoidable ( $2 \mathrm{~b}$ and $3 \mathrm{~b}$ ) by comparing prevention costs and eco-costs (or user-defined targets). The discussion insists on the benefits of prevention for (2a), of finding responsible suppliers for (3a), and of compensation for (1), (2b) and (3b). 
- Avoidance costs (single score) are presented as a potential hidden tax comprising prevention costs for (2a) and (3a) and compensation costs for (1), (2b) and (3b). If life cycle costing is also performed, the discussion shows whether a more expensive design option or scenario is justified by lower total life cycle costs. Otherwise, it is not environmentally optimal in any meaningful sense.

- The sensitivity analysis focuses on the global targets $\left(X_{j}\right)$ because they are the most uncertain parameters and the uncertainty in many variables depends on them.

The preceding procedure is recommended as long as the goal and scope of the LCA study is compatible with the aim of achieving zero life-cycle impacts through an optimal mix of prevention and compensation measures, or minimizing life-cycle impacts for a given budget while considering the opportunity to avoid more impacts elsewhere as implicitly part of the decision space.

Acknowledgements The authors would like to acknowledge the financial support of the industrial partners of the International Chair in Life Cycle Assessment (a research unit of the CIRAIG) and especially GDF SUEZ for the permission to use the LCA results. This research was also funded by a Natural Sciences and Engineering Research Council of Canada (NSERC) graduate scholarship and a Fonds de recherche du Québec-Nature et technologies (FQRNT) grant.

\section{References}

Azapagic A (1999) Life cycle assessment and its application to process selection, design and optimisation. Chem Eng J 73:1-21

Azapagic A, Clift R (1999) The application of life cycle assessment to process optimisation. Comput Chem Eng 23:1509-1526

Bernier E, Samson R, Maréchal F (2008) Multi-objective Design Optimization of a NGCC Power Plant with $\mathrm{CO} 2$ Capture Using Life Cycle Assessment Results. In: Ziębik A, Kolenda Z, Stanek W (eds) ECOS 2008, Cracow-Gliwice, Poland, June 24-27, 2008. The Silesian University of Technology, pp 1339-1346
Bernier E, Marechal F, Samson R (2010) Multi-objective design optimization of a natural gas combined cycle with carbon dioxide capture in a life cycle perspective. Energy 35:11211128

Bernier E, Marechal F, Samson R (2012) Optimal greenhouse gas emissions in NGCC plants integrating life cycle assessment. Energy 37:639-648

Bolliger R, Favrat D, Marechal F (2005) Advanced Power Plant Design Methodology using Process Integration and MultiObjective Thermo-Economic Optimisation. In: ECOS 2005, Trondheim, Norway, pp 777-784

Frischknecht R, Jungbluth N, Althaus H-J, Doka G, Dones R, Heck T et al (2005) The ecoinvent database: overview and methodological framework. Int J Life Cycle Assess 10(1):3-9

Gassner M, Baciocchi R, Marechal F, Mazzotti M (2009) Integrated design of a gas separation system for the upgrade of crude SNG with membranes. Chem Eng Process 48(9):1391-1404

Gerber L, Gassner M, Marechal F Integration of LCA in a thermoeconomic model for multi-objective process optimization of SNG production from woody biomass. In: Jezowski J, Thullie J (eds) ESCAPE19, Cracow, Poland, 2009. Elsevier, pp 1405-1410

Guillen-Gosalbez G, Grossmann IE (2010) A global optimization strategy for the environmentally conscious design of chemical supply chains under uncertainty in the damage assessment model. Comput Chem Eng 34:42-58

Hugo A, Pistikopoulos EN (2005) Environmentally conscious longrange planning and design of supply chain networks. J Clean Prod 13:1471-1491

Martinez P, Eliceche AM (2009) Multi objective optimization using life cycle environmental impact and cost in the operation of utility plants. Comput Aided Chem Eng 27:1869-1874

Simbolotti G (2006) CO2 Capture \& Storage. IEA Energy Technology Essentials. International Energy Agency. http://www.iea.org/techno/ essentials1.pdf Accessed 15 November 2011

USEPA (1999) Natural Gas Systems. Report on US methane emissions 1990-2020: inventories, projections, and opportunities for reductions, vol 3. Environmental Protection Agency, Washington, DC

Vogtländer JG, Bijma A (2000) A new calculation model for interpreting the results of an LCA, the 'Virtual Pollution Prevention Costs '99'. Int J Life Cycle Assess 5(2):113-124

Vogtländer JG, Brezet HC, Hendriks CF (2001) The virtual eco-costs ' 99 , a single LCA-based indicator for sustainability and the ecocosts - value ratio (EVR) model for economic allocation. A new LCA-based calculation model to determine the sustainability of products and services. Int J Life Cycle Assess 6(3):157-166

Vogtländer JG, Bijma A, Brezet HC (2002) Communicating the ecoefficiency of products and services by means of the eco-costs/ value model. J Clean Prod 10:57-67 